\title{
Thymolipomas in association with myasthenia gravis
}

\author{
Antonio Ríos Zambudio, MD, Juan Torres Lanzas, MD, María José Roca Calvo, MD, PhD, \\ Enrique Martínez Barba, MD, and Pascual Parrilla Paricio, MD, PhD, Murcia, Spain
}

$\mathrm{T}$ hymolipomas are rare, benign thymic lesions (2\%-9\% of thymic tumors), consisting of adipose tissue inside the thymus, which is slow growing ${ }^{1}$ and has scarce local and systemic manifestations (50\% diagnosed in routine radiologic studies). ${ }^{2}$ Myasthenia gravis (MG) is generally associated with and present in up to $30 \%$ of thymomas. ${ }^{1}$ However, association with thymolipomas is uncommon, with just 15 cases reported in the English-speaking literature (Medline 1967-August 2000). ${ }^{2-14}$

We report 3 new cases of this uncommon association and review the literature.

\section{Clinical Summary}

Two patients were women, and one was a man. The clinical presentation was general weakness, which increased during the course of the day. The patients had vertical diplopia and weakness of jaw movement. Two patients had dysphagia, more noticeably after eating, and one had dysphonia during conversations, which improved with rest.

In the 3 patients the physical exploration revealed a steady loss of strength on repeated movement, and the edrophony test results were positive. In 2 patients the antiacetylcholine receptor and antistriated muscle antibody levels were positive. Chest radiography was within normal limits. Mediastinal computed tomography showed no abnormalities in 1 patient. In the other 2 patients the computed tomograms showed a lesion at the thymus that was compatible with a diagnosis of thymoma. Electromyography with repetitive nerve stimulation, done in 2 patients, revealed a decrease of more than $20 \%$ in 1 patient and more than $15 \%$ in the other patient.

The treatment was implemented with anticholinesterases (pyridostigmine, $60 \mathrm{mg} / 6$ hours) and steroids (prednisone, $60 \mathrm{mg} / \mathrm{d}$ ), which failed to achieve total remission of the symptoms in 2 patients. The patients underwent thymectomy which extended to the whole of the mediastinal fat. Histologic study revealed thy-

\footnotetext{
From the Department of Thoracic Surgery, Department of General Surgery and Digestive Apparatus I, Department of Pathological Anatomy, Virgen de la Arrixaca University Hospital, Muricia, Spain.

Received for publication Jan 18, 2001; accepted for publication Feb 8, 2001.

Address for reprints: Antonio Rios Zambudio, MD, Avenida de la Libertad No. 208, Casillas, 30007, Murcia, Spain (E-mail: ARZRIOS@ @eleline.es).

J Thorac Cardiovasc Surg 2001;122:825-6

Copyright $\odot 2001$ by The American Association for Thoracic Surgery

$0022-5223 / 2001 \$ 35.00+0 \quad \mathbf{1 2 / 5 4 / 1 1 4 9 2 8}$

doi:10.1067/mtc.2001.114928
}

molipomas. During the postoperative period, 1 patient had a venous thrombosis that required anticoagulation.

After the operation, the MG symptoms improved partially, and the MG was controlled with small doses of corticosteroids and, in 2 patients, with small doses of anticholesterases. Twelve months after the thymectomy, 1 patient had dyspnea, and treatment was reimplemented with pyridostigmine $(60 \mathrm{mg} / 8$ hours $)$ and prednisone $(20 \mathrm{mg} / \mathrm{d})$, requiring hospital admission. Currently, 10 years after the operation, the patient's clinical symptoms are partially controlled with this medication. In the other patients currently, after 9 and 10 years, the symptoms are being partially controlled with pyridostigmine (30 mg/8 hours) and prednisone $(15 \mathrm{mg} / \mathrm{d})$.

\section{Comment}

The association of MG with thymolipomas is uncommon, and it is regarded by some authors as a simple epiphenomenon, although the fact that symptoms regress in most patients after thymectomy suggests that there is a relationship. The pathogenesis of thymolipoma is not clear, and there are currently 4 theories. ${ }^{2,9}$ One of the theories considers that the thymolipoma is a fatty involution of a thymoma, and therefore the thymolipomas would be true thymomas. Furthermore, the coexistence of thymolipoma with MG, other autoimmune diseases, or neoplastic conditions suggests that thymoma and thymolipoma are at least related tumors.

The patients with thymolipoma and MG differ from patients without MG in 2 ways: (1) thymolipomas with MG appear in older patients (20-30 years vs 40-50 years) ${ }^{12}$ and (2) mean thymolipoma weights are lower in patients with MG (100 g vs $1000 \mathrm{~g})$. This can be explained because thymolipomas without MG are usually diagnosed when they are large. ${ }^{9}$

Treatment for MG is initially medical, with anticholinesterases and corticosteroids and occasionally plasmapheresis. The surgical treatment of MG consists of thymectomy, which can be performed through a vertical sternotomy or cervicotomy; the former is recommended because it makes it easier to extend the thymectomy to the whole of the mediastinal fat, even with removal of both mediastinal pleurae. Extended thymectomy is currently the recommended treatment for MG.

Follow-up data are not easily interpretable because the reported postoperative periods are short, although thymectomy always leads to improvement (Table 1). However, a relapse of MG occurred in $4(26.7 \%)$ of the 15 published cases $^{2-14}$ but with such short follow-up periods in most cases that it is impossible to assess the long-term results. Our series has a long follow-up period ( $>9$ years). Two of the patients have shown a marked improvement, and the third, despite occasional relapses of MG, has also shown improvement. Only one of the patients, presented by Pan and colleagues, ${ }^{6}$ had total remission of the MG after thymectomy. 
TABLE 1. Cases of thymolipomas with MG reported in the English-speaking literature

\begin{tabular}{|c|c|c|c|c|c|c|c|c|}
\hline Case No. & Author & Age (y) & Sex & $\begin{array}{c}\text { Preoperative } \\
\text { evolution }\end{array}$ & $\begin{array}{c}\text { Thymolipoma } \\
\text { weight }\end{array}$ & $\begin{array}{c}\text { Postoperative } \\
\text { evolution }\end{array}$ & Relapse & $\begin{array}{c}\text { Follow-up } \\
\text { time }\end{array}$ \\
\hline 1 & Reintgen and colleagues ${ }^{3}$ & 60 & Male & $1 y$ & $100 \mathrm{~g}$ & Improvement & No & $3 \mathrm{mo}$ \\
\hline 2 & Otto and colleagues 4 & 56 & Male & $4 y$ & $93 \mathrm{~g}$ & Improvement & Yes (3 wk) & $1 \mathrm{mo}$ \\
\hline 3 & Mikkelsen ${ }^{5}$ & 61 & Male & $29 \mathrm{mo}$ & $65 \mathrm{~g}$ & Improvement & Yes (7 mo) & $8 \mathrm{mo}$ \\
\hline 4 & Pan and colleagues ${ }^{6}$ & 62 & Female & $7 \mathrm{mo}$ & $90 \mathrm{~g}$ & Complete remission & No & $24 \mathrm{mo}$ \\
\hline 5 & Pan and colleagues ${ }^{6}$ & 54 & Female & $6 y$ & - & Improvement & Yes (2 mo) & $18 \mathrm{mo}$ \\
\hline 6 & Olanow and colleagues ${ }^{7}$ & 62 & $?$ & $16 \mathrm{mo}$ & - & Improvement & No & $40 \mathrm{mo}$ \\
\hline 7 & Alfaro ${ }^{8}$ & 31 & Male & $10 y$ & $10 \mathrm{~g}$ & Improvement & No & $6 \mathrm{mo}$ \\
\hline 8 & Le Marc'hadour and colleagues ${ }^{9}$ & 52 & Male & $2 y$ & $185 \mathrm{~g}$ & Improvement & No & $18 \mathrm{mo}$ \\
\hline 9 & Moran and colleagues ${ }^{2}$ & - & - & - & - & - & - & - \\
\hline 10 & Moran and colleagues ${ }^{2}$ & - & - & - & - & - & - & - \\
\hline 11 & Toyama and colleagues ${ }^{10}$ & 48 & Male & $2 \mathrm{mo}$ & $680 \mathrm{~g}$ & Improvement & Yes (-) & - \\
\hline 12 & Sirpal and colleagues ${ }^{11}$ & 60 & Female & - & - & Improvement & - & - \\
\hline 13 & Verbist and colleagues $^{12}$ & 29 & Male & $4 y$ & $340 \mathrm{~g}$ & Improvement & No & $2 \mathrm{mo}$ \\
\hline 14 & Takamori and colleagues ${ }^{13}$ & 29 & Female & - & - & Improvement & - & - \\
\hline 15 & Hayashi and colleagues $^{14}$ & 29 & Female & - & - & Improvement & - & - \\
\hline 16 & Our series & 58 & Female & $7 \mathrm{mo}$ & $45 \mathrm{~g}$ & Improvement & Yes (12 mo) & $10 y$ \\
\hline 17 & Our series & 63 & Female & $6 \mathrm{mo}$ & $60 \mathrm{~g}$ & Improvement & No & $10 y$ \\
\hline 18 & Our series & 59 & Male & $2 y$ & $70 \mathrm{~g}$ & Improvement & No & $9 y$ \\
\hline
\end{tabular}

Although thymectomy does not usually resolve the clinical features of MG associated with thymolipoma, it does considerably improve symptoms and allows them to be controlled with a smaller dose of anticholinesterases and corticosteroids.

\section{References}

1. Strollo DC, Rosado de Christenson ML. Tumors of the thymus. $J$ Thorac Imaging. 1999; 14:152-71.

2. Moran CA, Rosado de Christenson M, Suster S. Thymolipoma: clinicopathologic review of 33 cases. Mod Pathol. 1995;8:741-4.

3. Reintgen D, Fetter BF, Roses A, McCarty KS Jr. Thymolipoma in association with myasthenia gravis. Arch Pathol Lab Med. 1978;102:463-6.

4. Otto HF, Löning TH, Lachenmayer L, Janzen WC, Gürtler KF, Fischer $\mathrm{K}$. Thymolipoma in association with myasthenia gravis. Cancer. 1985;1982:1623-8.

5. Millelsen B. Thymectomy in late-onset myasthenia gravis. Acta Neurol Scand. 1986;73:633-5.

6. Pan $\mathrm{CH}$, Chiang CY, Chen SS. Thymolipoma in patients with myasthenia gravis: report of two cases and review. Acta Neurol Scand. 1988;78:16-21.
7. Olanow CW, Russel JML, Roses AD. Thymectomy in late-onset myasthenia gravis. Arch Neurol 1989;39:82-3.

8. Alfaro A. Myasthenia gravis and thymolipoma. Acta Neurol Scand 1989;80:263.

9. Le Marc hadour F, Pinel N, Pasquier B, Dieny A, Stoebner P, Couderc P. Thymolipoma in association with myasthenia gravis. Am J Surg Pathol. 1991;15:802-9.

10. Toyama T, Mizuno T, Masaoka A, Shibata K, Yamakawa Y, Niwa H, et al. Pathogenesis of thymolipoma: report of three cases. Surg Today. 1995;25:86-8.

11. Sirpal YM, Chadha SK, Banarjee AK. Thymolipoma, a rare mediastino tumour, report of two cases and review of literature. Indian $J$ Cancer. 1995;32:23-6.

12. Verbist J, Sel R, Van Eyken P, Van Deun J, Schroe H. Myasthenia gravis associated with thymolipoma: a case report. Acta Chir Belg. 1997;97:97-9.

13. Takamori S, Hayashi A, Tayama K, Ohtxuka S, Hiraki H, Shirouzu K. Thymolipoma associated with myasthenia gravis. Scand Cardiovasc $J$. 1997;31:241-2.

14. Hayashi A, Takamori S, Tayama K, Mitsuoka M, Ohtsuka S, Aoyama Y, et al. Thymolipoma: clinical and pathological features-report of three cases and review of literature. Kurume Med J. 1997;44:141-6. 